\title{
CEA, CA 15-3 and CYFRA 21-1 in serum and pleural fluid of patients with pleural effusions
}

\author{
S. Romero, C. Fernández, J.M. Arriero, A. Espasa, A. Candela, \\ C. Martín , J. Sánchez-Payá
}

CEA, CA 15-3 and CYFRA 21-1 in serum and pleural fluid of patients with pleural effusion. S. Romero, C. Fernández, J.M. Arriero, A. Espasa, A. Candela, C. Martín, J. Sánchez-Payá. COERS Journals Ltd 1996.

ABSTRACT: The role of tumour marker assays in differentiating malignant from benign pleural effusions is not yet clear. This study was designed to prospectively assess the individual and combined diagnostic utility of three tumour markers in patients with pleural effusion.

Pleural and serum levels of carcinoembryonic antigen (CEA), carbohydrate antigen 15-3 (CA 15-3) and cytokeratin 19 fragment (CYFRA 21-1) were determined in 115 patients with pleural effusions (42 malignant and 73 benign). The diagnostic utility of each tumour marker was assessed using accuracy to determine the optimal cut-off point, whilst a logistic regression model was used to obtain the optimal combined test.

In serum, every marker showed an individual high specificity (over 97\%) for malignancy. The sensitivity of CEA, CA 15-3 and CYFRA 21-1 was 36, 48 and $31 \%$, respectively. In patients without renal failure, the sensitivity of CYFRA 21-1 rose to 53\%, while those of $\mathrm{CEA}$ and $\mathrm{CA}$ 15-3 remained almost unchanged. In pleural fluid, CYFRA 21-1 showed low sensitivity (32\%) and specificity (82\%), while CEA showed the highest sensitivity (57\%). Excluding patients with renal failure, the combined determination in serum of CEA, CA 15-3 and CYFRA 21-1 has a high accuracy $(\mathbf{8 8 \%})$, similar to that for CEA plus CA 15-3 in pleural fluid $(87 \%)$.

We conclude that CYFRA 21-1 is useless in pleural fluid and should not be used in serum for patients with renal failure. The combined determination of CEA, CA 15-3 and CYFRA 21-1 in serum may obviate its determination in pleural fluid. Eur Respir J., 1996, 9, 17-23.
Servicio de Neumología, Hospital General Universitario, Alicante, Spain.

Correspondence: S. Romero Italia $302^{\mathrm{a}}$ esc. $1^{\circ} \mathrm{D}$ 03003 Alicante Spain

Keywords: Adenocarcinoma carbohydrate antigen 15-3 carcinoembryonic antigen CYFRA 21-1 lung cancer pleural effusion tumour markers

Received: November 81994 Accepted after revision June 301995
Pleural effusion is a common problem in clinical practice. Even with the routine use of invasive procedures, such as thoracoscopy, 10-20\% of patients remain without diagnosis [1, 2]. Thoracocentesis and cytological examination have been proposed as the initial diagnostic approach to pleural effusions in patients in whom malignancy is clinically suspected. Cytological analysis of pleural fluid is reported to be diagnostic of malignant disease in $9-80 \%$ of cases, but in most series the success rate is about $60 \%[1,3]$. The simultaneous use of pleural needle biopsy has proved to be of limited (7\%) additive diagnostic value [1].

Although rather insensitive for the early diagnosis of cancer, the serum concentration of several tumour markers may be a reliable diagnostic aid in advanced stages $[4,5]$. Because neoplastic pleural effusions are almost always metastatic manifestations of malignant tumours elsewhere, the chance of a tumour marker elevation in such patients seems far from negligible.

Previous studies have tried to find biochemical markers in pleural fluid which could be of value in the differential diagnosis of pleural effusions [6-12]. The role, if any, of tumour marker assays in differentiating malignant from benign pleural effusions is not yet clear. However, some authors consider carcinoembryonic antigen (CEA) and other tumour markers to be of clinical diagnostic value [10-12].

The main purpose of the present study was to assess the diagnostic capacity in serum and pleural fluid of three different tumour markers, CEA, carbohydrate antigen 15-3 (CA 15-3) and cytokeratin 19 fragment (CYFRA 21-1). The latter, to our knowledge, has not previously been studied in pleural effusions.

\section{Material and methods}

We prospectively studied 120 consecutive patients with pleural effusion of unknown origin. Effusions were considered malignant if one of the following criteria was met: 1) demonstration of malignant cells at cytological 
examination or in a biopsy specimen; or 2) histologically proven primary malignancy with exclusion of any other cause known to be associated with pleural effusions. A pleural effusion was considered to be parapneumonic when there was an acute febrile illness, with purulent sputum and pulmonary infiltrate, in the absence of malignancy or diseases causing transudates. Tuberculous pleurisy was diagnosed by positive cultures for Mycobacterium tuberculosis or a pleural biopsy specimen showing typical epithelioid cell granulomata. A diagnosis of pulmonary embolus or infarction was made when there was a strong clinical suspicion and a high probability perfusion scan or abnormal angiogram. Congestive heart failure (CHF) was determined by an enlarged heart, pulmonary venous congestion on the radiograph, peripheral oedema, response to CHF treatment, and absence of malignancy or pulmonary infiltrates associated with an inflammatory process. Renal failure was considered when the creatinine clearance rate was $<40 \mathrm{~mL} \cdot \mathrm{min}^{-1}$, or when serum creatinine concentration was $>2.5 \mathrm{mg} \cdot \mathrm{dL}^{-1}$. Effusions were considered secondary to liver cirrhosis when they occurred in the absence of heart failure or malignancy.

At presentation, samples of pleural fluid and blood were taken and stored at $-20^{\circ} \mathrm{C}$ until tested. CEA levels were determined employing the solid-phase CEAenzyme immunoassay (EIA) (Abbott) and concentrations of CA 15-3 using a solid-phase sandwich EIA (CIS bio international) $[13,14]$. CYFRA 21-1 is a cytokeratin 19 fragment, whose precise recognition is made with two monoclonal antibodies, BM 19-21 and KS 19-1, obtained after immunization of mice with MCF-7 cells. For its determination, enzyme-linked immunosorbant assay (ELISA) CYFRA 21-1 (CIS bio international, Gif-surYvette, Cedex/France), a solid phase sandwich immunoradiometric assay was used. Two monoclonal antibodies (MoAbs) were prepared against sterically remote sites on the CYFRA 21-1 molecule, the first being coated on the ELISA solid phase; the second, radiolabelled with iodine 125, was used as a tracer. These MoAbs react against two epitopes of the cytokeratin 19 fragment (molecular weight $30 \mathrm{kDa}$ ). Radioactivity was counted in a gamma counter (Packard Mod. Cobra) with a microcomputer incorporated, and was expressed in cpm. The calculated concentrations of cytokeratin 19 were expressed in $\mathrm{ng} \cdot \mathrm{mL}-1$.

For CYFRA 21-1, intra-assay reproducibility, performed by measuring two different sera 10 times during the same assay, and expressed as coefficients of variation, was 4.7 and $6.3 \%$. In the same way, the interassay reproducibility, performed by measuring two different sera in five different assays, was 6.1 and $7.9 \%$. The detection limit, defined as the smallest detectable concentration different from 0 with a probability of $95 \%$, was 0.6 $\mathrm{ng} \cdot \mathrm{mL}^{-1}$.

Because some tumour markers have been found to be elevated in uraemia, the serum and pleural fluid concentrations of CEA, CA 15-3 and CYFRA 21-1 were also analysed, after excluding patients with renal failure.

All samples were assayed blind of clinical information.

\section{Statistical analysis}

The sample size was determined from a preliminary study with a few cases to demonstrate a difference between means within error limits: alpha $=5 \%$, beta $=10 \%$ for a ratio benign/malignant of $2 / 1$. After demonstrating that variables did not have a normal distribution using the Kolgomorov-Smirnov test, nonparametric statistical analyses were used. Differences between two independent groups were determined by means of the Mann-Whitney U-test. To compare differences between blood and pleural fluid values for every marker, we used the Wilcoxon signed-rank test for paired samples. The relationships between serum and fluid values for the same marker and between markers in both groups, benign and malignant, were assessed by means of Spearman correlation coefficients.

In an attempt to establish a sensitivity-specificity relationship, receiver-operating characteristic (ROC) curves were constructed using levels of tumour markers in patients with malignant pleural effusions and patients with benign pleural effusions as controls. In ROC curves, specificity is plotted from 100 to 0 on the $\mathrm{x}$-axis and sensitivity from 0 to 100 in the $y$-axis for each tumour marker. The more the curves approach the left upper corner, the better is the discrimination between benign and malignant pleural effusions. The cut-off values chosen were those with the highest accuracy. When more than one value showed equal accuracy, the one with the higher specificity was selected. The specificity, sensitivity and accuracy was calculated for every marker individually. To assess the utility of all three combined tumour markers in the discrimination between patients with benign and malignant pleural effusions, we used a logistic regression model (method enter). This technique makes it possible to obtain the optimal combined test, and analyses the relative simultaneous influence of every tumour marker. The cut-off point used to determine the probability of disease was 0.5. Values of $\mathrm{p}$ less than 0.05 were considered as significant.

\section{Results}

A definite diagnosis was obtained in 115 patients, 61 males and 54 females, with a mean age of $56 \pm 18$ (range 15-89) yrs. Seventy three pleural effusions were benign and 42 malignant. A detailed account of the aetiology is presented in table 1 and the histology of the patients with malignancy in table 2 .

Median and quartiles of serum and pleural fluid levels of CEA, CA 15-3 and CYFRA 21-1 in patients with benign and malignant effusions are presented in table 3 .

For every marker tested, serum and pleural fluid levels were significantly higher $(\mathrm{p}<0.001)$ in patients with malignant pleural effusions than in patients with benign pleural effusions.

In patients with benign pleural effusions, pleural fluid levels of CEA and CA 15-3 were significantly lower 
Table 1. - Aetiology of pleural effusions

\begin{tabular}{llr}
\hline Cause & & $\mathrm{n}$ \\
\hline \multirow{2}{*}{ Benign } & & 73 \\
& Parapneumonic & 20 \\
& Congestive heart failure & 14 \\
& Tuberculosis & 9 \\
& Nephrotic syndrome & 7 \\
& Traumatic or postsurgery & 6 \\
& Liver cirrhosis & 5 \\
& Pulmonary embolism & 5 \\
\multirow{5}{*}{ Malignant } & Others* & 7 \\
& & 42 \\
& Lung & 15 \\
& Breast & 12 \\
& Gynaecological & 5 \\
& Haematological & 2 \\
& Pleura & 2 \\
& Unknown & 3 \\
Idiopathic & Others & 3 \\
& & 5 \\
\hline \multirow{2}{*}{ Total } & & 120 \\
\hline
\end{tabular}

*: pancreatitis (2), collagen disease (2), Meigs' syndrome (1), asbestos exposure (1), glomerulonephritis (1); \#: pancreas (1), prostate (1), salivary gland (1).

Table 2. - Malignant effusions: histological types

\begin{tabular}{lr}
\hline Histological type & $\mathrm{n}$ \\
\hline Adenocarcinoma & 27 \\
Small cell carcinoma & 4 \\
Squamous cell carcinoma & 3 \\
Lymphoproliferative & 2 \\
Mesothelioma & 2 \\
Others* & 4 \\
\hline Total & 42 \\
\hline
\end{tabular}

*: undifferentiated carcinoma (2), embryonal carcinoma (1), adenoid cystic carcinoma (1).

Table 3. - Serum and pleural fluid levels of CEA, CA 15-3 and CYFRA 21-1 in patients with benign and malignant effusion

\begin{tabular}{lcc}
\hline & $\begin{array}{c}\text { Benign } \\
(\mathrm{n}=73)\end{array}$ & $\begin{array}{c}\text { Malignant } \\
(\mathrm{n}=42)\end{array}$ \\
\hline CEA ng·mL-1 & & \\
$\quad \begin{array}{l}\text { Serum } \\
\text { Pleural fluid }\end{array}$ & $1.4(0.8-2.0)$ & $4.6(1.2-10.5)^{* * *}$ \\
CA 15-3 IU·mL-1 & $0.6(0.5-1.1)$ & $6.9(0.7-23.3)^{* * *}$ \\
$\quad \begin{array}{l}\text { Serum } \\
\text { Pleural fluid }\end{array}$ & $15.8(10.9-19.9)$ & $26.8(16.7-68.3)^{* * *}$ \\
CYFRA 21-1 ng·mL-1 & $9.4(5.0-14.9)$ & $24.3(13.6-74.6)^{* * *}$ \\
$\quad \begin{array}{l}\text { Serum } \\
\text { Pleural fluid }\end{array}$ & $2.0(1.3-2.6)$ & $4.5(2.3-11.6)^{* * *}$ \\
\hline
\end{tabular}

Data are presented as median, and 25th-75th percentiles in parenthesis. CEA: carcinoembryonic antigen; CA: 15-3: carbohydrate antigen 15-3; CYFRA 21-1: cytokeratin 19 fragment. $* * *: \mathrm{p}<0.00001 ; * *: \mathrm{p}<0.001$, benign $v s$ malignant. $(\mathrm{p}<0.001)$ than in serum, while CYFRA 21-1 behaved in the opposite way. In patients with malignancy, pleural fluid levels of CYFRA 21-1 and CEA were significantly higher $(p<0.001$ and $p<0.01)$ than in serum. In these patients, serum levels of CA 15-3 were higher than in pleural fluid, although the differences were not significant.

In the group of 115 patients, we found a good correlation between serum and pleural fluid levels for every marker tested: CEA $\mathrm{r}=0.79(\mathrm{p}<0.0005)$; $\mathrm{CA} 15-3 \mathrm{r}=0.81$ $(\mathrm{p}<0.0005)$; and CYFRA 21-1 r=0.80 ( $<<0.0005)$. We also found a good correlation between serum and pleural fluid values for every marker in the group of patients with malignant effusions: CEA $\mathrm{r}=0.77(\mathrm{p}<0.0005)$; CA 15-3 r=0.79 $(\mathrm{p}<0.0005)$; and CYFRA 21-1 $r=0.82$ $(\mathrm{p}<0.0005)$; whilst in patients with benign pleural effusions no consistent relationship was found.

Individual levels of CEA, CA 15-3 and CYFRA 21-1 grouped as malignant and benign are plotted in figure 1 (serum) and figure 2 (pleural fluid).

The sensitivity, specificity and accuracy for every tumour marker in serum and pleural fluid are presented in table 4 . The serum tumour marker with the highest sensitivity (48\%) for malignancy was CA 15-3, although with a slightly lower specificity (97\%) than CEA (99\%) and CYFRA 21-1 (100\%). This highest individual sensitivity $(48 \%)$ is largely surpassed $(74 \%)$ when all three tumour markers are combined, but with a lower specificity $(92 \%)$.

In pleural fluid, CEA was the tumour marker with the highest sensitivity (57\%) and accuracy (83\%). When combined with CA 15-3 its accuracy increased to $87 \%$. CYFRA 21-1 showed the lowest sensitivity, and its specificity barely surpassed $80 \%$.

In table 5 the sensitivity, specificity and accuracy of every tumour marker are expressed, excluding the 11 patients with renal failure. In serum, the exclusion of patients with renal failure produced almost no change to the accuracy of CEA and CA 15-3, but increased that of CYFRA 21-1 from 75 to $81 \%$ when lowering the cutoff value from 8 to $4 \mathrm{ng} \cdot \mathrm{mL}^{-1}$.

The simultaneous influence of CEA, CA 15-3 and CYFRA 21-1 in the discrimination between benign and malignant pleural effusions is shown in tables 6 and 7 . In serum, CYFRA 21-1 showed the highest influence on the diagnosis of malignancy, with an odds-ratio of 1.44 (95\% confidence interval $(95 \%$ CI $) 1.12-1.86)$; and this influence was higher after excluding patients with renal failure, with an odds-ratio of 1.86 (95\% CI 1.14 3.05).

In pleural fluid, CYFRA 21-1 was not included in the model because it did not show a significant influence in discriminating malignancy. In this medium, CEA showed the highest influence in both groups of patients, with an odds-ratio of 1.56 (95\% CI $1.20-2.03)$ and $1.55(95 \%$ CI 1.40-1.70), respectively.

Pleural fluid cytology was negative in 18 of the 42 patients with malignant pleural effusion. Using the logistic regression model, the combination of all three tumour markers in serum identified 11 of these 18 patients as malignant. On the other hand, pleural fluid cytology 


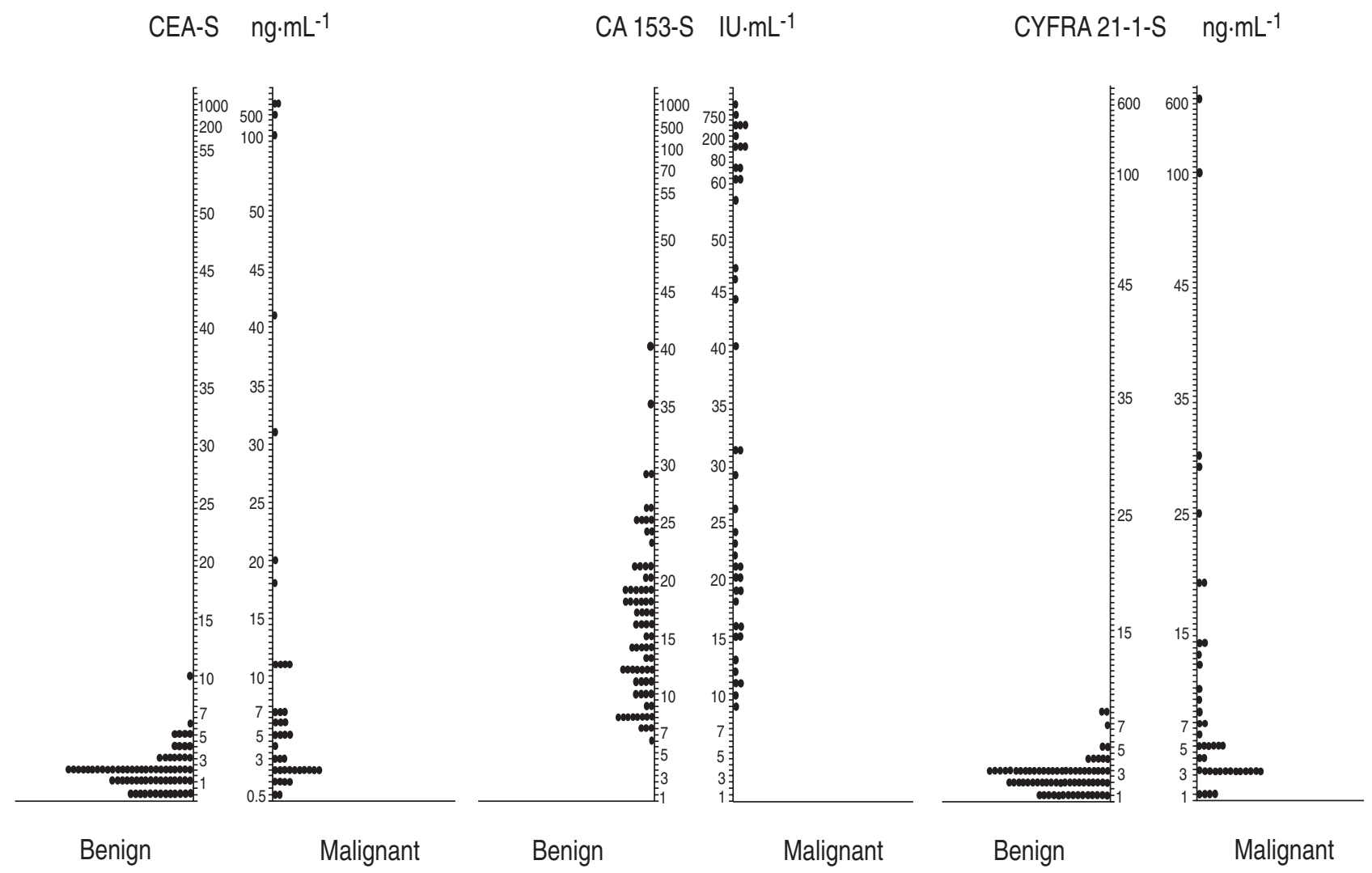

Fig. 1. - Individual serum (S) concentrations of carcinoembryonic antigen (CEA), carbohydrate antigen 15-3 (CA 15-3) and cytokeratin 19 fragment (CYFRA 21-1) in 73 patients with benign pleural effusions and 42 with malignant pleural effusions.

CEA-PF $n g \cdot \mathrm{mL}^{-1}$

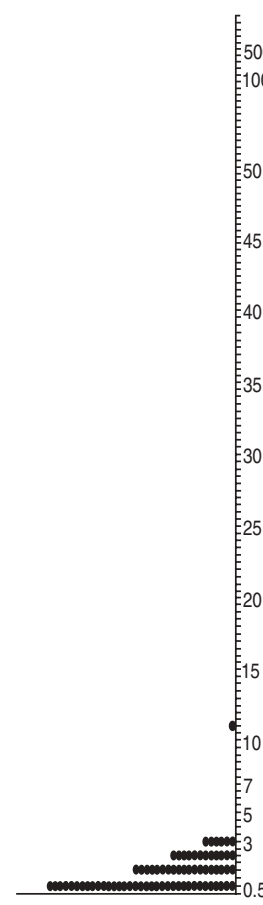

Benign
CA 153-PF IU.mL ${ }^{-1}$

CYFRA 21-1-PF $\mathrm{ng} \cdot \mathrm{mL}^{-1}$

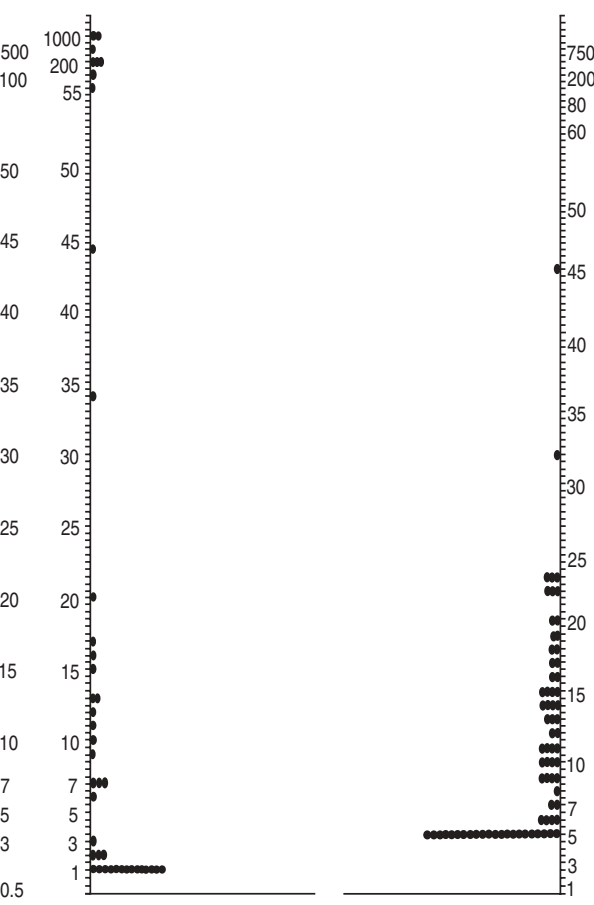

Malignant

Benign

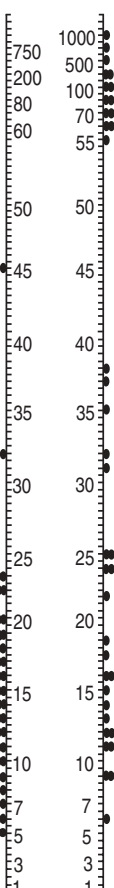

Malignant

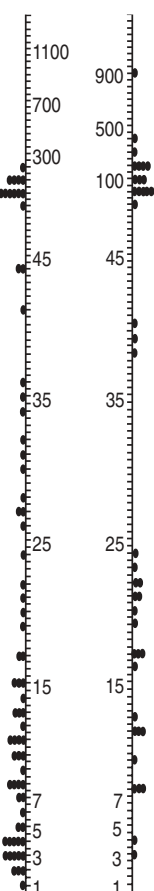

Benign

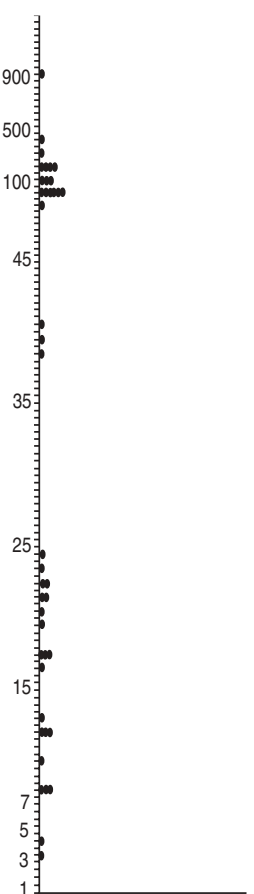

Malignant

Fig. 2. - Individual pleural fluid (PF) concentrations of carcinoembryonic antigen (CEA), carbohydrate antigen 15-3 (CA 15-3) and cytokeratin 19 fragment (CYFRA 21-1) in 73 patients with benign pleural effusions and 42 with malignant pleural effusions. 
Table 4. - Specificity, sensitivity and accuracy of CEA, CA 15-3, CYFRA 21-1 and cytology in 115 patients with pleural effusion

\begin{tabular}{|c|c|c|c|c|c|c|}
\hline \multirow[t]{2}{*}{ Test } & \multicolumn{2}{|c|}{ Specificity } & \multicolumn{2}{|c|}{ Sensitivity } & \multicolumn{2}{|c|}{ Accuracy } \\
\hline & $\mathrm{n}$ & $\%$ & $\mathrm{n}$ & $\%$ & $\mathrm{n}$ & $\%$ \\
\hline \multicolumn{7}{|l|}{ Serum } \\
\hline $\mathrm{CEA}>6 \mathrm{ng} \cdot \mathrm{mL}^{-1}$ & $72 / 73$ & 99 & $15 / 42$ & 36 & $87 / 115$ & 76 \\
\hline CA $15-3>30 \mathrm{IU} \cdot \mathrm{mL}^{-1}$ & $71 / 73$ & 97 & $20 / 42$ & 48 & $91 / 115$ & 79 \\
\hline CYFRA 21-1 $>8 \mathrm{ng} \cdot \mathrm{mL}^{-1}$ & $73 / 73$ & 100 & $13 / 42$ & 31 & $86 / 115$ & 75 \\
\hline CEA + CA $15-3+$ CYFRA $21-1^{\dagger}$ & & 92 & & 74 & & 85 \\
\hline \multicolumn{7}{|l|}{ Pleural fluid } \\
\hline CEA $>3 \mathrm{ng} \cdot \mathrm{mL}^{-1}$ & $72 / 73$ & 99 & $24 / 42$ & 57 & $96 / 115$ & 83 \\
\hline CA $15-3>25 \mathrm{IU} \cdot \mathrm{mL}^{-1}$ & $71 / 73$ & 97 & $20 / 42$ & 48 & $91 / 115$ & 79 \\
\hline CYFRA 21-1 $>50 \mathrm{ng} \cdot \mathrm{mL}^{-1}$ & $60 / 73$ & 82 & $16 / 42$ & 38 & $76 / 115$ & 66 \\
\hline $\mathrm{CEA}+\mathrm{CA} 15-3^{\dagger}$ & & 96 & & 71 & & 87 \\
\hline Cytology & $73 / 73$ & 100 & $24 / 42$ & 57 & $97 / 115$ & 84 \\
\hline
\end{tabular}

†: logistic regression model. For abbreviations see legend to table 3 .

Table 5. - Specificity, sensitivity and accuracy of CEA, CA 15-3, CYFRA 21-1 and cytology in 104 patients with pleural effusion (after excluding patients with renal failure)

\begin{tabular}{|c|c|c|c|c|c|c|}
\hline \multirow[t]{2}{*}{ Test } & \multicolumn{2}{|c|}{ Specificity } & \multicolumn{2}{|c|}{ Sensitivity } & \multicolumn{2}{|c|}{ Accuracy } \\
\hline & $\mathrm{n}$ & $\%$ & $\mathrm{n}$ & $\%$ & $\mathrm{n}$ & $\%$ \\
\hline \multicolumn{7}{|l|}{ Serum } \\
\hline CEA $>6 \mathrm{ng} \cdot \mathrm{mL}^{-1}$ & $63 / 64$ & 98 & $15 / 40$ & 38 & 78/104 & 75 \\
\hline CA $15-3>30 \mathrm{IU} \cdot \mathrm{mL}^{-1}$ & $63 / 64$ & 98 & $20 / 40$ & 50 & $83 / 104$ & 80 \\
\hline CYFRA 21-1 >4 ng.mL-1 & $63 / 64$ & 98 & $21 / 40$ & 53 & $84 / 104$ & 81 \\
\hline CEA + CA $15-3$ + CYFRA 21-1 & & 94 & & 80 & & 88 \\
\hline \multicolumn{7}{|l|}{ Pleural fluid } \\
\hline CEA $>3 \mathrm{ng} \cdot \mathrm{mL}^{-1}$ & $63 / 64$ & 98 & $24 / 40$ & 60 & $87 / 104$ & 84 \\
\hline CA $15-3>25 \mathrm{IU} \cdot \mathrm{mL}^{-1}$ & $63 / 64$ & 98 & $20 / 40$ & 50 & $83 / 104$ & 80 \\
\hline CYFRA 21-1 $>50 \mathrm{ng} \cdot \mathrm{mL}^{-1}$ & $52 / 64$ & 81 & $15 / 40$ & 38 & $67 / 104$ & 64 \\
\hline $\mathrm{CEA}+\mathrm{CA} 15-3^{\dagger}$ & & 95 & & 75 & & 87 \\
\hline Cytology & $64 / 64$ & 100 & $24 / 40$ & 60 & $88 / 104$ & 85 \\
\hline
\end{tabular}

$\dagger$ : logistic regression model. For abbreviations see legend to table 3.

was positive in 4 of the 11 patients with malignant pleural effusion that had not been detected by the optimal combination in serum of CEA, CA 15-3 and CYFRA 21-1.

\section{Discussion}

Virtually any carcinoma can metastasize to the pleura, but the most common primary sites are the lung, breast, stomach and ovary [3]. Based on this order of frequency, in addition to CEA, the most well-studied and widely known marker, we chose to test CA 15-3, a marker with apparent high specificity for cancer of breast origin $[4,15]$. To our knowledge, the potential diagnostic capacity of CYFRA 21-1 has not yet been studied in pleural fluid. However, we included CYFRA 21-1 because increased serum concentrations of this marker have been measured in patients with lung cancer [16-19], the most frequent type of metastatic pleural cancer in our clinical setting. The highest values of CYFRA 21-1 have been found in patients with squamous cell carcinoma (SCC), but superiority over SCC antigen has been demonstrated in all histological cell types of lung cancer; and only in the case of adenocarcinoma was its diagnostic value slightly lower than that of CEA. On the other hand, serum CYFRA 21-1 concentration generally increases with tumour size, lymph node involvement and the occurrence of metastases elsewhere [17].

Although usually evaluated in terms of sensitivity, specificity and accuracy, a variety of criteria have been used to assess the diagnostic value of tumour markers. Initially, a fixed specificity to choose the cut-off point has been recommended, but the precise value used has varied between groups. A specificity of $100 \%$, always desirable in clinical terms [7], may not be practical because of the poor sensitivity that may follow. This is the reason why some groups have agreed to use a specificity of $95 \%$ as the cut-off point [18]. Nevertheless, the alternative use of ROC-curves helps to preserve a higher sensitivity than when using the $100 \%$ specificity as point of reference, and in many cases avoids the burden of 5\% false positive cases. 
Table 6. - Combined influence of CEA, CA 15-3 and CYFRA 21-1 in the discrimination between patients with benign and malignant pleural effusions ( $n=$ 115)

\begin{tabular}{lccc}
\hline & Beta & SE & p-value \\
\hline Serum & & & \\
CEA & 0.30 & 0.12 & $<0.02$ \\
CA 15-3 & 0.08 & 0.03 & $<0.003$ \\
CYFRA 21-1 & 0.37 & 0.13 & $<0.004$ \\
Constant & -4.62 & 0.83 & $<0.0001$ \\
Pleural fluid & & & \\
CEA & 0.42 & 0.13 & $<0.001$ \\
CA 15-3 & 0.09 & 0.03 & $<0.005$ \\
Constant & -3.33 & 0.63 & $<0.0001$ \\
\hline
\end{tabular}

For abbreviations see legend to table 3 .

Table 7. - Combined influence of CEA, CA 15-3 and CYFRA 21-1 in the discrimination between patients with benign and malignant pleural effusions, after excluding patients with renal failure $(n=104)$

\begin{tabular}{lccc}
\hline & Beta & SE & p-value \\
\hline Serum & & & \\
CEA & 0.31 & 0.14 & $<0.02$ \\
CA 15-3 & 0.08 & 0.03 & $<0.01$ \\
CYFRA 21-1 & 0.62 & 0.25 & $<0.01$ \\
Constant & -5.09 & 1.00 & $<0.0001$ \\
Pleural fluid & & & \\
CEA & 0.43 & 0.13 & $<0.001$ \\
CA 15-3 & 0.10 & 0.03 & $<0.005$ \\
Constant & -3.51 & 0.72 & $<0.0001$ \\
\hline
\end{tabular}

For abbreviations see legend to table 3 .

Using ROC curves, we found that in patients with malignant pleural effusion, serum CYFRA 21-1 is a tumour marker with a relatively high diagnostic accuracy. However, we did not confirm the diagnostic superiority over CEA found in a previous study made in patients with lung carcinoma that included $43 \%$ with squamous cell type, and $36 \%$ of metastatic forms [17]. The high proportion of adenocarcinomas in our study, the histological type in which CYFRA 21-1 seems to show the lowest sensitivity [17-19], and the possibility that concentrations in serum of CYFRA 21-1 may be elevated earlier than those of CEA in less advanced forms of malignancy, could explain this discrepancy. On the other hand, when patients with renal failure are excluded, the accuracy of CYFRA 21-1 rises, although only slightly, over that of CEA.

Because the individual diagnostic serum sensitivity of CEA, CA 15-3 and CYFRA 21-1 was comparable and its specificity was high, the combination of all three markers seemed pertinent; and in fact, this approach resulted in a sharp increase in sensitivity and accuracy. This marked increase in sensitivity, which initially spoke for the combined use of all three markers in clinical practice, was due to the high percentage of cases $(45 \%)$ in which a single marker was positive. However, as occurred with CYFRA 21-1 individually, the combined logistic regression model showed a lowering in specificity to $92 \%$ when patients with renal failure were not excluded.
Some tumour markers have been found to be elevated in uraemia, among them the CEA [20, 21]. The true kinetics of the generation and elimination of most tumour marker antigens has not been examined. The potential role of the reticuloendothelial system in an increased generation, and the role of the renal tubules and glomerular filtration in a reduction of their clearance have been proposed as possible explanations [22]. Tumour markers with a low molecular weight, such as beta $2^{-}$ microglobulin, are readily released into the urine, and their serum concentrations depend on renal function. The molecular weights of CA 15-3 (290 kDa) and CEA $(200 \mathrm{kDa})$ make glomerular filtration an unlikely method of removal. The lower molecular weight of CYFRA 21-1 (40 kDa) may explain the higher influence of renal failure on its serum concentration found in the present study.

Despite showing a higher sensitivity for malignancy than cytology, the use of combined serum tumour markers does not obviate performing other procedures to exclude the possibility of a benign pleural effusion in a patient with malignancy. Nevertheless, on clinical grounds, we think that, in a high proportion of patients with malignancy, serum tumour markers reflect the extension of the tumour and the likelihood that another pathological manifestation, such as a pleural effusion, is linked to the presence of a metastatic deposit.

The results of the present study again confirm CEA as the most dependable tumour marker in pleural fluid $[9,10,13]$, where its sensitivity was $57 \%$, a value close to that of cytology in most series, and its specificity was $99 \%$. The CA 15-3, with an accuracy only $4 \%$ lower than that of CEA, showed a sensitivity of $48 \%$ with a specificity of $97 \%$, making this marker useful, either alone or in combination with other diagnostic procedures. In fact, the combined sensitivity of CEA plus CA $15-3$ was $71 \%$, although with a specificity slightly lower $(96 \%)$.

Rat pleural mesothelial cells express intermediate filaments typical both of epithelial cells and fibroblasts. Severe injuries, as often occur with infections of pleural space, are associated with extensive denudation and disruption of the basement membrane. The sequence of events leading to pleural repair may culminate in the development of areas of active pleural fibrosis, where fibroblasts show strong cytoplasmatic immunostaining for cytokeratins and vimentin [23]. This process may explain the high levels of cytokeratin 19 found in the pleural fluid of patients with inflammatory diseases, that forced us to raise the cut-off point for malignancy to obtain a specificity of $82 \%$ (18\% of false positives), still unacceptable for clinical purposes, and a sensitivity of only $38 \%$, lower than that for CEA and CA 15-3. This is the most important finding of this study, because, if confirmed, it would preclude the use of CYFRA 21-1 for diagnostic purposes in pleural fluid.

We conclude that when malignancy is suspected, the determination in serum of CEA, CA 15-3 and CYFRA 21-1 is of potential value in patients with pleural effusion of unknown aetiology. CYFRA 21-1 is useless in pleural fluid and should not be used in serum for patients 
with renal failure. The combined determination of CEA, CA 15-3 and CYFRA 21-1 in serum may obviate its determination in pleural fluid.

\section{References}

1. Udaya BS, Prakash MD, Reiman HN. Comparison of needle biopsy with cytological analysis for the evaluation of pleural effusion: analysis of 414 cases. Mayo Clin Proc 1985; 60: 158-164.

2. Ryan CJ, Rodgers RF, Unni KK, Hepper NGG. The outcome of patients with pleural effusion of indeterminate cause at thoracotomy. Mayo Clin Proc 1981; 56: 145-149.

3. Sahn SA. The pleura. Am Rev Respir Dis 1988; 138: 184-243.

4. Colomer R, Ruibal A, Salvador L. Circulating tumor marker levels in advanced breast carcinoma correlate with the extent of metastatic disease. Cancer 1989; 64: 1674 1681.

5. Bates SE. Clinical applications of serum tumor markers. Ann Intern Med 1991; 115: 623-627.

6. Booth SN, Lakin G, Dykes PW, Burnett D, Bradwell AR. Cancer-associated proteins in effusion fluids. $J$ Clin Pathol 1977; 30: 537-540.

7. Thomson NC, Rana B, Ratcliffe JG. Carcinoembryonic antigen assay in pleural effusions. Ann Intern Med 1979; 90: 720-721.

8. Martínez-Vea A, Gatell JM, Segura F, et al. Diagnostic value of tumoral markers in serous effusions. Cancer 1982; 50: 1783-1788.

9. Tamura S, Nishigaki T, Moriwaki Y, et al. Tumor markers in pleural effusion diagnosis. Cancer 1988; 61: 298-302.

10. Niwa Y, Kishimoto H, Shimokata K. Carcinomatous and tuberculous pleural effusions: comparison of tumor markers. Chest 1985; 87: 351-355.

11. Vladutiu AO, Brason FW, Adler RH. Differential diagnosis of pleural effusions: clinical usefulness of cell marker quantitation. Chest 1981; 79: 297-301.

12. Romero Candeira S, Martín Serrano C, Serralta Buades J, Cabezas Jiménez A, López Martínez M, Hernández Blasco L. Comparación de la rentabilidad inicial de la citología, biopsia y antígeno carcinoembrionario en el estudio de los derrames pleurales. Med Clin (Barc) 1988; 91: 45-49.

13. Romero Candeira S, Hernández Blasco L, Senent Español $\mathrm{C}$, et al. Utilidad de los marcadores tumorales en el diagnóstico de los derrames pleurales: antígeno carcinoembrionario, alfa fetoproteína y orosomucoide. Med Clin (Barc) 1986; 86: 439-443.

14. Romero S, Hernández L, Salar A, García Sevila R, Espasa MA, Martín Serrano C. Valor de la determinación del CA 15-3 en el diagnóstico de los derrames pleurales malignos. Rev Clin Esp 1992; 190: 339-343.

15. Hayes DF, Zurawski VR, Kufe DW. Comparison of circulating CA 15.3 and carcinoembryonic antigen levels in patients with breast cancer. J Clin Oncol 1986; 38 : 1542-1550.

16. Debus E, Moll R, Franke WW, Weber K, Osborn M. Immunohistochemical distinction of human carcinomas by cytokeratin typing with monoclonal antibodies. Am J Pathol 1994; 114: 121-130.

17. Ebert W, Leichtweist B, Schapöhler B, Muley Th. The new tumor marker CYFRA is superior to SCC antigen and CEA in the primary diagnosis of lung cancer. Tumor Diagn Ther 1993; 14: 91-99.

18. Stieber P, Dienemann H, Hasholzner U, et al. Comparison of cytokeratin fragment 19 (CYFRA 21-1), tissue polypeptide antigen (TPA) and tissue polypeptide specific antigen (TPS) as tumour markers in lung cancer. Eur J Clin Chem Clin Biochem 1993; 31: 689-694.

19. Pujol JL, Grenier J, Daurès JP, Daver A, Pujol H, Michel FB. Serum fragment of cytokeratin subunit 19 measured by CYFRA 21-1 immunoradiometric assay as a marker of lung cancer. Cancer Res 1993; 53: 61-66.

20. Cases A, Filella X, Molina R, Ballesta AM, López-Pedret $\mathrm{J}$, Revert L. Tumor markers in chronic renal failure and hemodialysis patients. Nephron 1991; 57: 183-186.

21. Brandstetter RD, Graziano VA, Wade MJ, Saal SD. Carcinoembryonic antigen elevation in renal failure. Ann Intern Med 1979; 91: 867-868.

22. De Santo NG, Veneroso S, Capodicasa G, Crisci A, Giordano C. Tumor markers in uremia: carcinoembryonic antigen, neuron-specific enolase, carbohydrate antigen CA-50 and alfafetoprotein. Am J Nephrol 1986; 6: 458-463.

23. Antony VB, Sahn SA, Mossman B, Gail DB, Kalica A. Pleural cell biology in health and disease. Am Rev Respir Dis 1992; 145: 1236-1239. 